\title{
Seeing as Understanding: The Importance of Visual Mathematics for our Brain and Learning
}

\author{
Jo Boaler*, Lang Chen, Cathy Williams and Montserrat Cordero
}

Stanford Graduate School of Education \& Stanford Cognitive \& Neuroscience Lab, Stanford University, USA

\begin{abstract}
A few weeks ago the silence of my Stanford office was interrupted by a phone call. A mother called to tell me that her 5-year old daughter had come home from school crying because her teacher had not allowed her to count on her fingers. A few weeks afterwards, when I told my undergraduate mathematics class that visual mathematics was really important, one of them asked: but it is only for low levels of math, isn't it?
\end{abstract}

Keywords: Visual mathematics; Brain and learning

\section{Introduction}

The teacher and student referenced above are reflecting what is a common belief in education - that visual mathematics is for lower level work, and for struggling or younger students, and that students should only work visually as a prelude to more advanced or abstract mathematics. As Thomas West, author, states, there is a centuriesold belief that words and mathematical symbols are "for serious professionals - where - as pictures and diagrams" are "for the lay public and children". This idea is an example of a damaging myth in education, and this paper will present compelling brain evidence to help dispel the myth. We will also provide examples of ways that visual mathematics may be integrated into curriculum materials and teaching ideas across grades $\mathrm{K}-16$. The provision of ways to see, understand and extend mathematical ideas has been under developed or missed in most curriculum and standards in the US, that continue to present mathematics as an almost entirely numerical and abstract subject. Yet when students learn through visual approaches, mathematics changes for them, and they are given access to deep and new understandings. The brain evidence we will share, helps us understand the impact of visualizing and seeing, to all levels of mathematics, and suggests an urgent need for change in the ways mathematics is offered to learners.

Good mathematics teachers typically use visuals, manipulative and motion to enhance students' understanding of mathematical concepts, and the US national organizations for mathematics, such as the National Council for the Teaching of Mathematics (NCTM) and the Mathematical Association of America (MAA) have long advocated for the use of multiple representations in students' learning of mathematics. But for millions of students in US mathematics classes, mathematics is presented as an almost entirely numeric and symbolic subject, with a multitude of missed opportunities to develop visual understandings. Students who display a preference for visual thinking are often labeled as having special educational needs in schools, and many young children hide their counting on fingers, as they have been led to believe that finger counting is babyish or just wrong. This short paper, collaboration between a neuroscientist and mathematics educators, shares stunning new evidence from the science of the brain, showing the necessity and importance of visual thinking - and, interestingly, finger representations - to all levels of mathematics.

\section{What Does the Brain Science Say?}

In recent years, scientists have developed a more nuanced understanding of the ways our brains work when we study and learn mathematics. Our brains are made up of 'distributed networks', and when we handle knowledge, different areas of the brain light up and communicate with each other. When we work on mathematics, in particular, brain activity is spread out across a widely-distributed network, which include two visual pathways: the ventral and dorsal visual pathways. Neuroimaging has shown that even when people work on a number calculation, such as $12 \times 25$, with symbolic digits ( 12 and 25) our mathematical thinking is grounded in visual processing (Figure 1).

A widely distributed brain network underpins the mental processing of mathematics knowledge [1]. The area of the brain shown in green, which is part of the dorsal visual pathway, has reliably been shown to be involved when both children and adults work on mathematics tasks. This area of the brain particularly comes into play when students consider visual or spatial representations of quantity, such as a number line [2]. A number line representation of number quantity has been shown in cognitive studies to be particularly important for

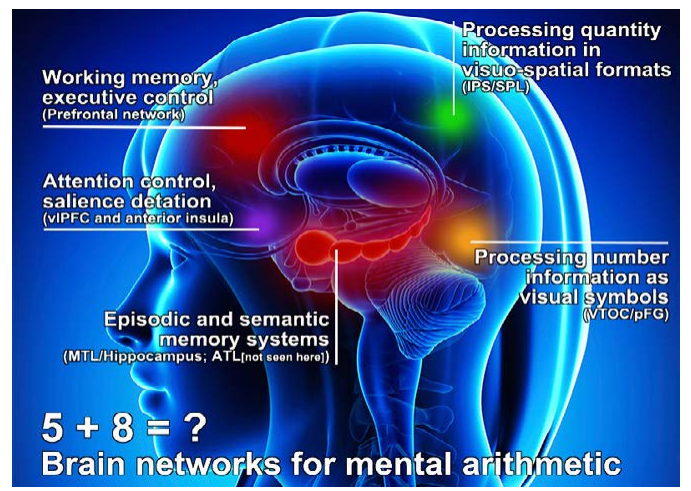

Figure 1: Distributed networks.

*Corresponding author: Jo Boaler, Professor of Mathematics Education, Stanford Cognitive and Systems Neuroscience Lab, Stanford University, USA, Tel: 650-7234076; E-mail: joboaler@stanford.edu

Received September 20, 2016; Accepted October 05, 2016; Published October 12, 2016

Citation: Boaler J, Chen L, Williams C, Cordero M (2016) Seeing as Understanding The Importance of Visual Mathematics for our Brain and Learning. J Appl Computat Math 5: 325. doi: 10.4172/2168-9679.1000325

Copyright: ( 2016 Boaler J, et al. This is an open-access article distributed under the terms of the Creative Commons Attribution License, which permits unrestricted use, distribution, and reproduction in any medium, provided the original author and source are credited. 
the development of numerical knowledge and a precursor of children's academic success [2-5].

Researchers even found that after four 15-minute sessions of playing a game with a number line, differences in knowledge between students from low-income backgrounds and those from middleincome backgrounds were eliminated [6].

The researchers in the study highlighted the importance of students learning numerical knowledge through linear representations and visuals. This is just one of many studies that show that visual mathematics problems help students and raise achievement. The brain research sheds light on this, as it is showing that the dorsal visual pathway is the core brain region for representing the knowledge of quantity.

One yet-to-be published study from our colleagues at Stanford, with children between the ages of 8 and 14, showed that as children get older they develop part of the ventral visual pathway, shown in orange in Figure 1, and the brain becomes more sensitive and specialized in representing visual number forms. The study also showed an important and increased interaction between the two visual pathways. This indicates that as children learn and develop, the brain becomes more interactive, connecting the visual processing of symbolic number forms, such as the number 10, with visuo-spatial knowledge of quantity, such as an array of dots or another visual representation [7]. Different areas of the brain are involved when we think mathematically, including the frontal networks shown in red and purple, the medial temporal lobe and, importantly, the hippocampus - the horseshoe shaped area in red. The important point that we want to stress in this paper is that the neurobiological basis of mathematics cognition involves complicated and dynamic communication between the brain systems for memory, control and detection and the visual processing regions of the brain.

A compelling and rather surprising example of the visual nature of mathematical activity in the brain comes from a new study on the ways that the brain uses representations of fingers, well beyond the time and age that people use their fingers to count. The different studies on the brain's use of finger representations give fascinating insights into human learning and clear implications for mathematics classrooms.

\section{Mathematical Understanding and Fingers}

Berteletti and Booth [8] studied one specific region of our brain that is dedicated to the perception and representation of fingers, known as the somatosensory finger area of the brain. Remarkably brain researchers know that we "see" a representation of our fingers in our brains, even when we do not use fingers in a calculation. Berteletti and Booth found that when 8-13 year olds were given complex subtraction problems, the somatosensory finger area lit up, even though the students did not use their fingers.

We "see" a representation of fingers in our brains when we calculate.

The researchers also found that this finger representation area was involved to a greater extent with more complex problems that involved higher numbers and more manipulation. Penner-Wilger [9] found that even university students' somatosensory knowledge of fingers predicts their calculation scores. She also found that finger perceptions in Grade 1 predict performance on number comparison and estimation in Grade 2 (2009). Researchers assess whether children have a good awareness of their fingers by touching the finger of a student - without the student seeing which finger is touched - and asking them which finger is being touched to perceive and represent their own fingers, they develop better representations of their fingers, which leads to higher mathematics achievement $[10,11]$. Researchers found that when 6 year old's improved the quality of their finger representation they improved in arithmetic knowledge, particularly subitizing1, counting and number ordering. Remarkably the 6 year old's finger representation was a better predictor of future mathematics success than their scores on tests of cognitive processing. Subitizing is the process of estimating small quantities such as 1,2 or 3 without counting.

One of the recommendations of the neuroscientists conducting these important studies is that schools focus on finger discrimination. The researchers not only point out the importance of number counting on fingers, for brain development and future mathematics success, they advocate that schools help students' discriminate between their fingers. This seems particularly significant to us given that schools pay no attention to finger discrimination now and no published curriculum that we know of encourages this kind of mathematical work. Instead, many teachers have been led to believe that finger use is babyish or to be moved on from, as quickly as possible. Kumon, an after school program used by thousands of parents in 49 countries, tells parents that finger counting is a "no no" and parents who see children counting on their fingers should report them to the instructor [12].

There is debate among neuroscientists about the precise mechanisms by which finger knowledge improves mathematics achievement, but clear agreement on one thing, development of finger representations is critically important. Brian Butterworth, leading brain researcher in this area, states that if students are not learning about numbers through thinking about their fingers, numbers "will never have a normal representation in the brain" [13]. Despite the clear evidence on the importance of finger use, dangerous instructions to ban finger use are communicated to teachers and parents. Telling students not to use their fingers to count or represent quantities is akin to halting their mathematical development. Fingers are probably our most useful visual aid, critical to mathematical understanding, and brain development, that endures well into adulthood. The need for and importance of finger perception could even be a part of the reason that pianists, and other musicians, often display higher mathematical understanding (see http://www.livescience.com/51370-does-music-give-you-math-skills. $\mathrm{html}$ ). The neuroscientist's recommend that fingers be regarded as the link between numbers and their symbolic representation, and an external support for learning arithmetic problems.

No US curriculum materials that we know of include activities for helping students develop finger discrimination, so we have developed a range of activities for use in classroom and homes that can be accessed in the appendix below and at https://www.youcubed.org/category/ visual-math/, to help this development in children and prompt further ideas and work in this area. Importantly teachers should celebrate and encourage finger use among younger learners and enable learners of any age to strengthen this brain capacity through finger counting and use. This does not mean that learners should keep counting on fingers as they move through school, it means that anyone who needs to advance their perception and knowledge of their fingers and count on their fingers should do so, at any age, as it is critical for their brain development. It is important to remove the stigma from counting on fingers and to see this activity as inherently important and valuable.

\section{Embodied Cognition}

The evidence that is accumulating, showing the importance of visual pathways and the connections between different pathways in the brain, resonates with an area of research that is known as 'embodied 
cognition'. Most people think of the mind and the body as completely separate entities with the mind holding knowledge and abstractions, and the body passively taking ideas from the mind to the physical world by, for example, saying ideas out loud or writing them down. But embodied cognition researchers point out that many of our mathematical concepts are held in visual and sensory motor memories.

Embodied cognition researchers note the ways we posture, gaze, gesture, point, and use tools when expressing mathematical ideas as evidence of our holding mathematical ideas in the motor and perceptual areas of the brain [14] - which is now supported by brain evidence. The researchers point out that when we explain ideas, even when we don't have the words we need, we tend to draw shapes in the air. We might also use space around us to "spread out" our ideas. For example, deciding that one side of a table represents an idea, and pointing back to it when we want to refer to that idea even though there is nothing actually there, just our previous motions designating the space [15]. The researchers in this field don't assume the separation of mind and body, and have concluded that the body is an intrinsic part of cognition, that the parts of our brain that control perception and movement of our bodies, are also involved in knowledge representation [16]. It is fairly well known that knowledge of dance, or sport is held in sensory motor areas of our brain (Figure 2).

Some embodied cognition researchers have concluded that as we use gestures when we think mathematically, teachers should use gestures to ground mathematical thinking, alongside their verbal explanations [15] but researchers do not advocate 'giving' gesture schemes to students in mathematics classrooms and prefer that students be given opportunities to develop their own. We gesture because we see, experience and remember mathematics physically and visually, and greater emphasis on visual and physical mathematics will help students understand mathematics. Giving students someone else's gestures seems counterproductive in this regard. Instead we should give students more experiences of visual and even physical mathematics, as we expand upon below.

\section{Implications for Classrooms and Homes}

The new knowledge that we have, showing the visual processing of mathematical ideas, may explain the many research studies indicating that teachers who emphasize visual mathematics and who use wellchosen manipulative encourage higher achievement for students, not only in elementary school but middle school, high school and college [17]. Consistent with this, if we ask the best teachers about the

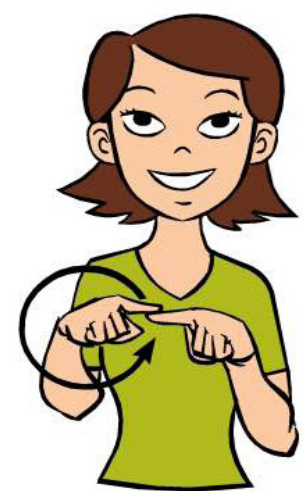

Figure 2: A teacher drawing a circle in the air when describing circumference to students. importance of visual representations they will usually share the rich knowledge they hold, of the deep understanding that is enabled - both from teachers introducing mathematical ideas visually, and students using visuals to think and make sense of mathematics. Entire volume from the Mathematical Association of America (MAA) have been devoted to the encouragement of visual mathematics in college [18]. When our team at youcubed (a Stanford center dedicated to giving research based mathematics resources to teachers and parents) created a free set of visual mathematics lessons for grades 3-9 last summer, they were downloaded one quarter of a million times by teachers and used in every state across the US. Eighty-eight per cent of teachers said they would like more of the activities, and $83 \%$ of students reported that the visual activities enhanced their learning of mathematics.

Despite the prevalence of the idea that drawing, visualizing or working with models is low level or for young children, some of the most interesting and high level mathematics is predominantly visual. Maryam Mirzakhani made headlines across the world recently when she became the first woman to win the coveted Field's medal, the greatest prize in mathematics. Her work is almost entirely visual. Other mathematicians described her theories as "beautiful", "stunning" and connecting previously unconnected theories in mathematics. Children may go through hundreds of hours of calculating only ever seeing numbers and symbols but mathematicians rarely if ever, solve a problem without visual representations. As West reflects: "It's masochism for a mathematician to do without pictures" [4].

Yet another reason that visual mathematics should be used in schools to a greater extent is the nature of the knowledge needed for today's high-tech world. Years ago workplace knowledge was based on words and numbers, but the new knowledge of the world is based largely on images, that are 'rich in content and information' [19]. Most companies now have large amounts of data, known as "big data" and the largest growing job of the future is the task of making sense of the data, including seeing data patterns, visually. Computer scientists and mathematicians at Stanford and elsewhere now see patterns in data that could never have been picked up by statistical techniques. When we trialed our visual mathematics activities that we shared on youcubed.org in a local middle school, a parent stopped me and asked what we had done in class that week. She told me that her daughter had always said she disliked and couldn't do math, but after working on our visual tasks she came home saying she had changed her mind and she could see a future in math. Why? The math was open, creative and visual [20]. Such activities not only offer deep engagement, new understandings, and visual brain activity, but they show students that mathematics can be an open and beautiful subject, rather than a fixed, closed and impenetrable subject. Visual mathematics is not important only for some students - struggling or so called "visual" thinkers, nor is it only a prelude for abstract mathematics - visual mathematics is important for everyone, at all levels of mathematics.

It is hardly surprising that students feel that mathematics is inaccessible and uninteresting when they are plunged into a world of abstraction and numbers. This is particularly ironic when a different teaching approach of visual, creative mathematics - is available to all teachers and learners (https://www.youcubed. org/week-ofinspirational-math/). Mathematics classes in the US do not reflect the knowledge we have of the importance of visual mathematics approaches, as most curriculum standards and published textbooks do not invite visual thinking. Many textbooks provide pictures but these are often irrelevant to the mathematical ideas presented. The Common Core pays more attention to visual work in the K-8 standards, than 
many previous sets of standards, but the high school content of the Common Core leads teachers to remain committed to numerical and abstract thinking. Where the Common Core does encourage visual work, it is usually encouraged as a prelude to the development of abstract ideas, rather than a tool for seeing and extending mathematical ideas and strengthening important brain networks.

A few years ago Howard Gardner proposed a theory of multiple intelligences, suggesting that people have different approaches to learning, such as a visual, kinesthetic or logical approach. This idea helpfully expanded people's thinking about intelligence and competence, but was often used in unfortunate ways in schools, leading to the labeling of students as particular type of learners who were then taught in different ways. But people who are not strong visual thinkers probably need visual thinking more than anyone. Everyone uses visual pathways when we work on mathematics and we all need to develop the visual areas of our brains.

The problem of mathematics in schools is it has been presented, for decades, as a subject of numbers and symbols, ignoring the potential of visual mathematics for transforming students' mathematical experiences and developing important brain pathways.

The new brain research showing the importance of visual thinking should also prompt changes in the ways we view students in schools. Mathematics classrooms promote the students who memorize and calculate well, even when these students are weak at visualizing, modeling or thinking about concepts visually.

When the converse is true and students are weak memorizers or number users, but produce strong visual ideas and representations, they are often referred to special education classes. This could be the reason that some of our greatest scientists - Albert Einstein and Thomas Edison for example were written off by teachers and even labeled as "stupid." Einstein often shared that all of his thinking was visual and he struggled, later, to turn his visual ideas into words and symbols [19]. Visual mathematics is widely thought of as being appropriate for younger or struggling students and as a prelude to the "more important" abstract mathematics. It is true that abstract ideas can come from and be aided by visual mathematics, but visual ideas can also come from abstract mathematics and extend them to much higher levels. They can also inspire students and teachers, to see mathematics differently, to see the creativity and beauty in mathematics and to understand mathematical ideas.

\section{Putting Research Ideas into Practice}

Over recent years I have worked with colleagues, teaching math summer camps to $7^{\text {th }}$ and $8^{\text {th }}$ grade students. Last summer we ran a math camp at Stanford, in which students had 18 math lessons with myself, Cathy Williams, and other teachers. At the end of camp the students described their experiences as transforming their views of mathematics and, importantly, their own potential. When they were given a district test that they had taken at the end of the school year there was an average of 50\% improvement in test scores across the 81 students. A video of the camp can be seen here (https://www.youcubed. org/youcubed-summer-camp-2015/). In our math camps we teach the students visual algebra through pattern study and generalization, exploring the worlds of linear and quadratic functions.

Algebra classes are often dedicated to students rearranging symbols, and students approach important mathematical concepts, such as functions, through numbers and symbols, without any visual understandings. In our teaching we approached algebra visually, as well as numerically and symbolically. In one activity, for example, we asked students to look briefly at a border around a square and work out how many squares were in the border, without counting them [21] (Figure 3).

The students thought about the number of squares in the border in many different ways, shown below, which they described at first numerically and then algebraically.

The students' different ways of seeing were a resource for engaging discussions between students and the development of different algebraic generalizations, which students learned were equivalent. When students see patterns growing in different ways [22], they are equally fascinated and engaged, and they learn, deeply, about functional growth, a major area of the US curriculum.

In one striking example of powerful mathematics learning we asked the students to consider distance-time graphs, which is an area that is notoriously challenging, even for college students [23]. We invited students to learn about distance, time, and velocity, through actually walking the line of a distance-time graph, using a motion sensor that tracked their movement. Further details of these activities are given here (https://www.youcubed.org/category/visual-math/) (Figure 4).

The students stunned district visitors when a girl, who was one of the lowest achievers in her grade, gave a perfect explanation of the graphing of velocity, rejecting a common misconception that is held by millions of students. When the students explained the concept they gestured, with their hands, to show the movement, again showing that their understanding of the concept was held in sensory-motor memories. The teaching of velocity through movement was clearly
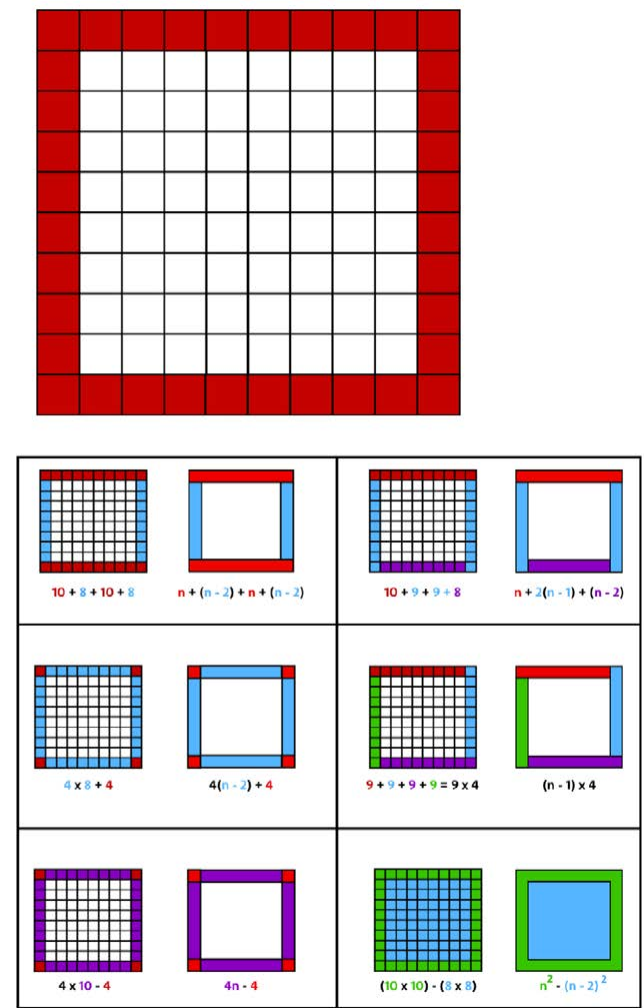

Figure 3: Students opinion about the number of squares in the border in many different ways. 


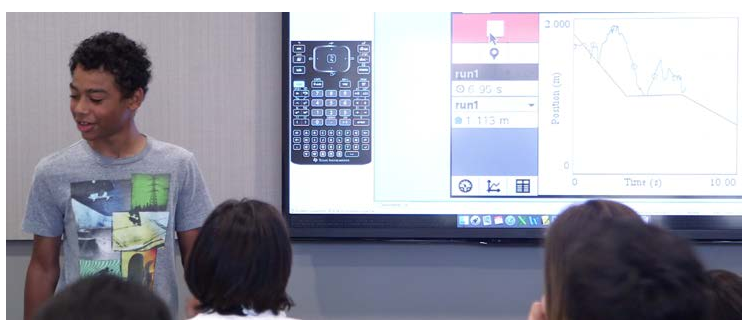

Figure 4: Students to learn about distance, time, and velocity, through actually walking the line of a distance-time graph.

powerful for the students and motion is a helpful resource for teachers. But other visual teaching is just as important.

To engage students in productive visual thinking, they should be asked, at regular intervals, how they see mathematical ideas, and to draw what they see. Drawing mathematical ideas helps mathematics users of any level, including mathematicians, to formulate ideas and develop understandings. Students can be given activities with visual questions and they can be asked to provide visual solutions to questions (examples across K-16 grades can be seen in Visual Mathematics Activities and our Youcubed task page). New dynamic software and high quality apps and games (see https://www.youcubed.org/category/teaching-ideas/ mathapps/), are also powerful in developing students' visual brain pathways. Other suggestions teachers can give to students are to represent ideas in a multitude of ways, such as through pictures, models, graphs, even doodles or cartoons. More ideas for the visualization of mathematics are given in Boaler $[20,22]$ and on youcubed.org.

At the end of camp one girl reflected that she had: "Never before seen a mathematical idea".

This seems to be a sad indictment of her US mathematics education. Another student reflected:

"It's like the way, the way our schools did it. It's like very black and white. And the way people do it here (in summer camp), it's like very colorful, very bright. You have very different varieties you're looking at. You can look at it one way, turn your head, and all of a sudden you see a whole different picture."

When mathematics classrooms focus on numbers, status differences between students often emerge, to the detriment of classroom culture and learning, with some students stating that work is "easy" or "hard" or announcing they have "finished" after racing through a worksheet. But when the same content is taught visually, it is our experience that the status differences that so often beleaguer mathematics classrooms, disappear. Thomas West also notes the equalizing effect of visual work, describing the time that various experts from academic disciplines came together to think visually, showing mutual respect towards each other and to different ideas, in ways that rarely happen when work is numerical [19]. It seems possible that visual mathematics may contribute to equity, in valuing students' thinking in different ways, as well as encouraging deep engagement, as we have found all students to be excited to see mathematical ideas, and from there they have developed higher levels of understanding and performance.

In our extensive work with school districts, teachers have also been inspired by visual and open mathematics. When we give teachers visual experiences of ideas that they have only previously encountered numerically and abstractly, such as multiplication facts or algebra, they gain insights into mathematical concepts and ideas they had never before experienced, and start to understand more deeply. They also feel empowered. Inviting people to think visually about mathematics is liberating for teachers and students alike. Mathematics is a multidimensional subject, and problems can be solved with numeric, abstract or visual mathematical pathways - we now know that our brain networks are correspondingly multi-dimensional and need to be developed and used. It is our belief that learners would develop stronger mathematical understanding if we helped them develop the visual networks in their brains, increasing their ability to work mathematically with a fully developed brain network.

\section{Conclusion}

\section{Three recommendations for teaching and parenting,}

The classroom and parental implications of the emerging science of the brain that shows that mathematical thinking centrally involves visual pathways - and finger representations - are important to consider. Here are 3 recommendations for educators and parents:

1. Encourage and celebrate students' visual approaches and replace the idea that strong mathematics learners are those who memorize and calculate well. Recent PISA evidence, from millions of students, tells us that the students who approach mathematics with a memorization approach are the lowest achieving students in the world [24]. We also need to end the myth that good mathematics performance is about calculating fast; a number of mathematicians are working to change this idea, explaining how they think slowly and deeply about mathematics [25]. Fast calculation is not what is needed in high-level mathematics work. Strong mathematics learners are those who think deeply, make connections and visualize. When I introduce math problems to my Stanford students I say - "I don't care about speed, in fact I am unimpressed by those who finish quickly, that shows you are not thinking deeply. Instead I would like to see interesting and creative representations of ideas". After a few lessons the students broaden their views of mathematics, and they start to blow me away with their creative thinking and insightful representations, and the new understandings they develop.

2. Focus on finger discrimination and encourage finger use. Successful mathematics users have well developed finger representations in their brains that they use into adulthood. Finger discrimination even predicts mathematics success. When we stop students using fingers we stop an important part of their mathematical development. Teachers who have stopped students using fingers are doing what they thought was best for children, as the idea that finger use is babyish, and needs to be discouraged, is widespread. But we now have the knowledge that should change this and encourage teachers to focus on finger discrimination and use in classrooms to a much greater extent.

3. Importantly, mathematics teaching and learning needs to become more visual - there is not a single idea or concept that cannot be illustrated or thought about visually. Elementary school, ironically more than higher-grade levels, is often obsessively numerical. Students are made to memorize math facts, and plough through worksheets of numbers, with few visual or creative representations of mathematics or invitations to work visually, often because of policy directives and faulty curriculum guides. By the time most students leave elementary school they have developed the idea that visuals and manipulative are babyish, fingers should never be used, and mathematical success is about memorizing numerical methods. As students move up through the grades they continue on overly numerical and symbolic pathways. 
Algebra classes are often composed entirely of symbol manipulation and the idea that visuals or manipulative are a mere prelude to abstract mathematics becomes instantiated. What would mathematics look like if it were visual, instead of merely numerical? Our appendix and companion document, Visual Mathematics Activities, shows a range of examples, for different grade levels.

Some scholars note that it will be those who have developed visual thinking that will be 'at the top of the class' in our new hightech workplace that increasingly draws upon information visualization technologies and techniques, in business, technology, art and science [19]. In our education system it is important not to prioritize any 'type of learner' over others or even to give the idea that it is productive to take one learning approach and focus upon it. The brain science supports this - work on mathematics draws from different areas of the brain and we want students to be strong with visuals, numbers, symbols and words. One of the aims of this paper is to point out that many schools are not encouraging this broad development in mathematics now and we urgently need to expand the ways we think about mathematics, and to teach it as the visual and multidimensional subject that it is.

Jo Boaler is professor of mathematics education at Stanford University, co-founder of youcubed, and author of the new book Mathematical Mindsets: Unleashing Students Potential through Creative Math, Inspiring Messages and Innovative Teaching (2016) Wiley.

Lang Chen is a postdoctoral scholar in the Department of Psychiatry and Behavioral Science at Stanford University. His research focuses on the development of knowledge representations, currently of math and language, in the brain.

\section{Cathy Williams is co-founder and director of youcubed.}

Monsterrat Cordero is an undergraduate student at Stanford University pursuing a BS in mathematics and interdisciplinary honors in education and a founding youcubed member.

\section{References}

1. Menon V (2014) Arithmetic in child and adult brain. In: Cohen KR, Dowker A (eds.) Handbook of mathmatical cognition. Oxford University Press, London.

2. Kucian K, Grond U, Rotzer S, Henzi B, Schönmann C, et al. (2011) Mental number line training in children with developmental dyscalculia. Neurolmage 57: 782-795.

3. Hubbard EM, Piazza M, Pinel P, Dehaene S (2005) Interactions between number and space in parietal cortex. Nature Reviews Neuroscience 6: 435-448.

4. Siegler RS, Booth JL (2004) Development of Numerical Estimation in Young Children. Child Development 75: 428-444.

5. Schneider M, Grabner RH, Paetsch J (2009) Mental number line, number line estimation, and mathematical achievement: Their interrelations in grades 5 and 6. Journal of Educational Psychology 101: 359

6. Siegler RS, Ramani GB (2008) Playing linear numerical board games promotes low income children's numerical development. Developmental science 11: 655-661.

7. Battista C, Ngoon T, Chen T, Chen L, Kochalka J, et al. (2016) Longitudina development and emergence of specialized functional brain systems supporting cognition in children.

8. Berteletti I, Booth JR (2015) Perceiving fingers in single-digit arithmetic problems. Frontiers in Psychology 6: 226.
9. Penner-Wilger M (2013) Symbolic and non-symbolic distance effects in number comparison and ordinarily tasks. Canadian Journal of Experimenta Psychology/Revue Canadienne De Psychologie Expérimentale 67: 281-282.

10. Ladda AM, Pfannmoeller JP, Kalisch T, Roschka S, Platz T, et al. (2014) Effects of combining 2 weeks of passive sensory stimulation with active hand motor training in healthy adults. PloS one 9: e84402.

11. Gracia-Bafalluy M, Noël MP (2008) Does finger training increase young children's numerical performance? Cortex 44: 368-375.

12. Kumon Connections Newsletter (2014) News from your Center.

13. Brian B (1999) The mathematical brain. Macmillan, London.

14. Nemirovsky R, Rasmussen C, Sweeney G, Wawro M (2012) When the classroom floor becomes the complex plane: Addition and multiplication as ways of bodily navigation. Journal of the Learning Sciences 21: 287-323.

15. Alibali MW, Nathan MJ (2012) Embodiment in mathematics teaching and learning: Evidence from learners' and teachers' gestures. Journal of the learning sciences 21: 247-286.

16. Hall R, Nemirovsky R (2012) Introduction to the special issue: Modalities of body engagement in mathematical activity and learning. Journal of the Learning Sciences 21: 207-215.

17. Sowell EJ (1989) Effects of Manipulative Materials in Mathematics Instruction Journal for Research in Mathematics Education 20: 498.

18. Zimmermann W, Cunningham S (1991) Visualization and the nature of mathematics. In Visualization in teaching and learning mathematics: A project. Washington DC: Mathematical Association of America.

19. West T (2014) Thinking like Einstein: Returning to our visual roots with the emerging revolution in computer information visualization. Prometheus Books New York.

20. Boaler J (2016) The Many Colors of Math: Engaging Students through Collaboration and Agency. Journal of Mathematical Behavior.

21. Boaler J, Humphreys C (2005) Connecting Mathematical Ideas: Middle Schoo Cases of Teaching and Learning. Ports-mouth: Heinemann.

22. Boaler J (2016) Mathematical Mindsets: Unleashing Students' Potential through Creative Math, Inspiring Messages and Innovative Teaching. Chappaqua, Jossey-Bass/Wiley, New York.

23. Clement $J$ (1989) The Concept of Variation and Misconceptions in Cartesian Graphing. Focus on Learning Problems in Mathematics 11: 77-87.

24. Organisation for Economic Co-operation and Development (OECD) Learning by Heart May Not be For the Best.

25. Schwartz I (2001) A Mathematician Grappling with his Century Birkhäuser 